\title{
Serum and Sputum Iron Trends Distinguigh Responders and Non- Responders to Treatment of Cystic Fibrosis Pulmonary Exacerbation
}

\author{
Alex H Gifford ( $\nabla$ alex.h.gifford@hitchcock.org ) \\ Deepika Polineni \\ University of Kansas Medical Center \\ Jianghua He \\ University of Kansas Medical Center \\ Jessica L D'Amico \\ Maine Medical Center \\ Dana B Dorman \\ Dartmouth-Hitchcock Medical Center \\ Molly A Williams \\ Dartmouth-Hitchcock Medical Center \\ Amanda B Nymon \\ Dartmouth College Geisel School of Medicine \\ Akshu Balwan \\ MaineGeneral Health \\ Theodore Budden \\ University of Kansas Medical Center \\ Jonathan B Zuckerman \\ Maine Medical Center
}

Dartmouth-Hitchcock Medical Cente https://orcid.org/0000-0002-6404-3793

\section{Research}

Keywords: iron, cystic fibrosis, hepcidin, interleukin-6, exacerbation

Posted Date: August 5th, 2020

DOI: https://doi.org/10.21203/rs.3.rs-52287/v1

License: (c) (i) This work is licensed under a Creative Commons Attribution 4.0 International License. Read Full License 


\section{Abstract}

Background: The cystic fibrosis (CF) community seeks to explain the heterogeneity of pulmonary exacerbation (PEX) treatment outcomes. Studies suggest that certain substances in serum and sputum offer objective evidence of PEX onset in people with CF (PwCF) and identify those at risk for inadequate treatment responses. However, it is clinically impractical to measure most of these substances, and a lack of correlative clinical information limits their utility as drivers of medical decision-making. Here, we questioned whether routinely available indices of iron homeostasis and systemic inflammation could identify PwCF with and without sustained symptom and lung function responses to PEX treatment.

Methods: We prospectively evaluated health-related quality-of-life (HRQoL) and lung function and measured biochemical indices associated with iron homeostasis in serum and sputum in twenty adults during a PEX cycle. We classified subjects as sustained symptom-responders (SRs) or non-sustained symptom-responders (NSRs) based on the absence or presence, respectively, of worsened symptom scores following initial improvement during PEX treatment. We used linear mixed models (LMMs) to explore whether treatment-related trends in lung function and hematologic and sputum parameters of interest differed between SRs and NSRs.

Results: We identified ten SRs and ten NSRs. Subjects were adults with baseline lung function and symptom burden similar to other CF cohorts in the literature. SRs and NSRs were treated for similar durations. SRs had higher model-predicted trends in lung function than NSRs during treatment. Serum interleukin-6 (IL-6) and serum hepcidin-25 fell during treatment in SRs and NSRs. Trends in serum and sputum iron levels differed significantly between SRs and NSRs.

Conclusions: In adults with CF treated for PEX, symptomatic non-response may be associated with lack of lung function improvement, initial increase but terminal decline in serum iron concentration, and initial decline but terminal increase in sputum iron concentration. Future work is needed to confirm the findings and understand possible mechanisms for these alterations in iron homeostasis during CF PEX.

\section{Background}

Cystic fibrosis (CF) is an autosomal recessive disease caused by mutations in the gene for CFTR, a chloride channel that regulates salt and water transport across epithelial cells (1). CFTR dysfunction results in dehydrated airway secretions in the lungs of people with CF (PwCF), which promotes infection, inflammation, and premature death from respiratory failure $(2,3)$. The pathophysiology of CF includes episodes of worsened respiratory and/or constitutional signs and symptoms called pulmonary exacerbations (PEXs). PEXs undermine health-related quality of life (HRQoL) $(4,5)$, accelerate loss of lung function $(6,7)$, increase risk of death or lung transplant (7), and are costly, as they usually require hospitalization (8). In 2018, one-third of the 30,775 PwCF in the Cystic Fibrosis Foundation Patient Registry (CFFPR) had PEXs treated with intravenous (IV) antibiotics (9), underscoring the prevalence of these events and the substantial resources required for their treatment.

For reasons that remain incompletely understood, there is marked heterogeneity to outcomes of guideline-driven PEX treatment (10) in the U.S. CF population. Registry-based (11), single-center (12), and multicenter (13) studies have shown that $15-35 \%$ of patients do not regain at least $90 \%$ of their baseline lung function (percent-predicted forced expiratory volume in one second, FEV1\%). Female sex, malnutrition, CFrelated diabetes (CFRD), lung infection by multidrug-resistant pathogens, and large declines in lung function prior to treatment have been associated with suboptimal outcomes, including incomplete recovery of FEV1\% (11-13). Studies have also determined that the magnitude of FEV1\% recovery is higher when PEXs are treated in the hospital rather than in the outpatient setting $(14,15)$ and that 30-day risk of retreatment with IV antibiotics is higher if patients are never treated in the hospital (16). Because clinical practices vary among, and even within, CF care centers $(13,17,18)$, and PEX treatment outcomes remain heterogeneous, there is an unmet need to characterize patient phenotypes and correlative biochemical indices that clinicians might use to improve the efficiency and accuracy with which they diagnose and treat PEXs and to personalize therapies $(19,20)$. Trends in these indices could complement serial symptom scores in individuals with poor baseline lung function who are less likely to have significant treatment-related increases in FEV1\% (13), thus providing additional objective evidence of recovery that might be leveraged to reduce overtreatment.

Inflammation is a pathophysiologic hallmark of CF (21), but limited information exists about correlations between inflammatory mediator levels and lung function (22-24) or HRQoL (22) during PEXs because few studies have monitored PwCF throughout a complete PEX cycle (i.e., from baseline health to PEX onset and serially during PEX treatment to recovery). Accordingly, there remains a need to identify biochemical tests that are easily performed in clinical laboratories and are able to identify groups of PwCF with different physiologic and symptomatic responses to PEX treatment. Concentrations of certain cytokines and protein effectors of inflammation in blood and sputum from PwCF measured before, during, and after PEXs could have diagnostic and prognostic utility $(12,24-27)$. With the exceptions of calprotectin and C-reactive protein, clinical laboratories do not routinely quantify these substances in biological samples, which is a barrier to their widespread application as tools to monitor PEX treatment responses $(28,29)$.

Page 2/16 
Interleukin-6 (IL-6), a pro-inflammatory cytokine found at high concentrations in blood and sputum from PwCF (30), stimulates the liver to produce hepcidin-25 (31), a hormone that reduces blood iron levels by attenuating gastrointestinal iron absorption (32) and triggering mononuclear cells to sequester iron (33). In adults with CF, we found that serum iron levels were lower and sputum iron, serum IL-6, and serum hepcidin-25 levels were higher immediately before PEX treatment (34), a pattern consistent with the mechanisms by which IL-6 and hepcidin-25 link iron homeostasis to inflammation (35). A limitation of our previous work (34) was the omission of serial assessments of lung function and HRQoL to compare to biomarkers of iron homeostasis.

The current study had a master aim of phenotyping cohorts of adults with CF with respect to HRQoL, FEV1\% and other clinical metrics, and laboratory indices of iron homeostasis measured at pre-specified points during a complete PEX cycle. Assuming, as the literature would suggest (11-13), that our study participants would heterogeneously benefit from PEX treatment, we tested a primary hypothesis that those with non-sustained improvements in HRQoL would have non-sustained improvements in lung function and those with sustained improvements in HRQoL would have sustained improvements in lung function, thus establishing two cohorts with distinct clinical responses. We then tested a secondary hypothesis that biomarkers of iron homeostasis in the cohort with non-sustained improvements in HRQOL and lung function would reflect an unresolved inflammatory state at the end of PEX treatment characterized by higher levels of serum IL-6, serum hepcidin-25, and sputum iron, and lower levels of serum iron than those found in the cohort with sustained HRQoL and lung function responses.

\section{Methods}

\subsection{Study Subjects and Design}

This was a prospective observational study of 20 adults diagnosed with CF according to standards (36). Subjects were hospitalized for PEX treatment on the general medical wards of Dartmouth-Hitchcock Medical Center (DHMC) or Maine Medical Center (MMC) between September 2014 and July 2017. Attending pulmonologists (JBZ, AHG) decided whether chronic medications $(37,38)$ used by subjects prior to admission were continued or withdrawn, and they also determined the classes and duration of IV antibiotics administered to subjects. Subjects could finish courses of IV antibiotics at home at the pulmonologist's discretion, but they returned to clinic for their end of treatment assessments.

\subsection{Diagnostic Testing}

We used clinical autoanalyzers to perform complete blood counts and to measure serum iron, transferrin saturation (TSAT), and total iron binding capacity (TIBC). The clinical microbiology laboratory at each site performed sputum cultures. We assayed spontaneously expectorated sputum samples for inorganic iron (expressed as $\mathrm{ng}$ of iron per $\mathrm{mg}$ of sample) using inductively coupled plasma-mass spectrometry (39). Spirometry was performed according to ATS/ERS standards (40). We measured serum IL-6 levels in triplicate using solid phase sandwich enzyme-linked immunosorbent assay (ELISA) kits (Human Quantikine ${ }^{\circledR}$; R\&D Systems; Minneapolis, MN) according to manufacturer's instructions. We extrapolated serum IL-6 levels from standard curves using mean values in calculations. The detection range of the IL-6 ELISA was 3.1-300 pg/ml. Serum hepcidin-25 was measured by competitive ELISA (Intrinsic LifeSciences, LLC; La Jolla, CA) using published methods (41). The lower limits of quantitation and detection for the serum hepcidin- 25 assay were $19 \mathrm{ng} / \mathrm{ml} \mathrm{and} 5 \mathrm{ng} / \mathrm{ml}$, respectively.

\subsection{Definition of PEX Cycle}

We used the Akron Pulmonary Exacerbation Score (PES) to define baseline health and PEX onset. The Akron PES is a tool designed to standardize the use of antibiotics to treat CF PEXs. The instrument classifies data collected during routine office visits into three domains (systemic signs and symptoms, pulmonary signs and symptoms, and objective measurements). The Akron PES ranges from 0 to 30 with higher scores corresponding to greater symptom burden, and a score $\geq 5$ signals PEX onset (42). We defined the baseline visit as the most recent encounter before PEX onset when a subject had an Akron PES $<5$ and the pulmonologist did not prescribe antibiotics. We defined PEX onset as the first encounter after the baseline visit when Akron PES was $\geq 5$ and the pulmonologist admitted the subject to the hospital for IV $A B X$. The end of treatment visit occurred on the last day of IV antibiotics.

\subsection{Subject Self-Assessment of HRQoL}

We used the CF Respiratory Symptom Diary (CFRSD) to obtain HRQoL data from subjects. The CFRSD is a validated eight-question, selfcompleted instrument designed to evaluate the symptom burden of PwCF during the most recent 24 -hour epoch $(43,44)$. We used the 
CFRSD under license from the Seattle Quality of Life Group at the University of Washington. We summed raw CFRSD responses and then calculated the Chronic Respiratory Infection Symptom Score (CRISS) using a conversion table provided with the instrument (45). The CFRSD-CRISS ranges from 0 to 100 with higher scores corresponding to higher symptom burden.

\subsection{Definitions of Sustained and Non-Sustained Symptom Responder Cohorts}

We classified subjects whose CFRSD-CRISS steadily declined between PEX onset and the end of treatment visit as sustained symptomresponders (SRs). We classified subjects whose CFRSD-CRISS initially declined but then increased before the end of treatment visit as nonsustained symptom-responders (NSRs).

\subsection{Statistical Analyses}

Median values of continuous variables were compared between cohorts using the Wilcoxon rank sum test. Categorical variables were compared between cohorts by Chi-square tests. Kaplan-Meier analysis was used to compare durations of PEX treatment between cohorts. Linear mixed models (LMMs) were used to test whether the trajectory of each outcome differed between cohorts. Variables with rightskewed distributions were natural log-transformed before inclusion in LMMs. Linear and quadratic terms for time after PEX onset and interactions between these time variables and cohort designation were tested in a hierarchical order: quadratic interaction, linear interaction, quadratic time term, and linear time term. The quadratic term for time was used to allow a non-linear time trend, and no higher order terms such as the cubic term were considered due to the small sample size. If the quadratic interaction term was significant $(p<0.05)$ or borderline $(0.05<p<0.1)$, the full model was kept. Otherwise, the quadratic interaction term was removed from the model, and the significance of the linear interaction term was examined. This process was stopped when a significant or borderline result was found or when all variables were removed from the model. All LMMs included a constant term to adjust for between-group differences in the outcome of interest at PEX onset. A final model with the quadratic and/or linear interaction term(s) suggested a potential difference of time trend between cohorts for the outcome of interest. Plots of the estimated mean trajectories with point-wise confidence intervals were used to show between-cohort differences in time trend. LMMs were also used to separately examine associations between the change in each with the change in CFRSDCRISS during PEX treatment. In these models, the outcome was the repeated measures of CFRSD-CRISS after PEX onset, and the predictor was the change in each index from day 0 and CFRSD-CRISS at day 0 , which was included to control for the effect of regression to the mean. Due to the small sample size, no control for multiple tests was applied, and because this study was hypothesis-generating, borderlinesignificant terms were retained in the final models.

\section{Results}

\subsection{Characteristics of Study Subjects at Baseline Visit}

We collected baseline visit data from 30 subjects, but only 20 of them had protocol-defined PEXs (Fig. 1). Two-thirds of subjects with PEXs were enrolled at DHMC, and the remainder were enrolled at MMC (Table 1). There were equal numbers of males and females. In general, subjects were older adults with advanced lung disease, as evidenced by low FEV1\%. Sixty percent of the cohort was homozygous for the F508del-CFTR mutation, and all but one of the other subjects was heterozygous for the F508del-CFTR mutation. Akron PES was uniformly $<5$ points. Sputum cultures revealed a single pathogen in $55 \%$ of subjects and two pathogens in $45 \%$ of subjects. Median number of chronic medications used by subjects to promote lung health (38) was 4 with a range of 1-5. Dornase alfa (95\%) and hypertonic saline (80\%) were used most commonly. Only three subjects $(15 \%)$ took one of the two CFTR modulator drugs $(46,47)$ available when the study was conducted (Table 1). Summary statistics for observations made during baseline visits on subjects without PEXs are provided as a supplement (Table S1).

\subsection{Identification of two cohorts with distinct symptomatic responses to PEX treatment}

Inspection of raw within-subject CFRSD-CRISS data in the form of "spaghetti plots" revealed two discrete patterns of variation during PEX treatment. Ten SRs had a steady decline in CFRSD-CRISS (Fig. 2A), and ten NSRs had an initial decline and terminal rebound in CFRSDCRISS (Fig. 2B). Median CFRSD-CRISS at the baseline visit (Table S1) and PEX onset were statistically similar between SRs and NSRs. The LMM for CFRSD-CRISS after PEX onset as a function of time showed a highly significant interaction between cohort and the quadratic time term, implying different time trends between cohorts (Table S2). The estimated mean trajectories and their 95\% confidence intervals (Cls) are plotted in Fig. 2C. Here, the trajectory of the SRs had a consistent decreasing trend, whereas that of NSRs initially decreased but then started increasing toward the end of treatment. The estimated trends (Fig. 2C) are consistent with the observed raw data in Fig. 2B. Kaplan-Meier estimator curves based on the length of hospital stay (Fig. S1) showed that median treatment durations for SRs (13.5 days) and NSRs (15.0 days) were not statistically different $(p=0.54)$. 


\subsection{Different Trends in FEV1\% between SRs and NSRs during PEX treatment}

SRs had higher median FEV1\% than NSRs at their baseline visits $(p<0.05)$ (Table S1) but not at PEX onset $(p=0.94)$. Like the LMM for CFRSD-CRISS, the LMM for FEV1\% showed a significant interaction between cohort and the quadratic time term, suggesting different time trends for FEV1\% between SRs and NSRs during treatment (Table S3). Estimated trajectories and $95 \%$ Cls for FEV1\% are shown in Fig. 3. For NSRs, FEV1\% remained almost flat during treatment, while that of SRs increased shortly after treatment initiation and leveled off at the end of treatment.

\subsection{Similar trends toward lower serum IL-6 and hepcidin-25 levels between SRs and NSRs}

Median serum concentrations of IL-6 and serum hepcidin-25 were not statistically different between SRs and NSRs at baseline (Table S1). Log transformation was applied to serum hepcidin- 25 and serum IL-6 before modeling as the two variables were highly right-skewed. The LMMs for both variables had an interaction between cohort and linear time term with borderline-significant $p$-values $(0.05<p<0.1)$. Quadratic interaction terms were dropped, as p-values were >0.1) (Table S4 and Table S5). No plots of the estimated trajectories are included for these borderline cases. Thus, the analytic approach did not show statistically significant differences in serum IL- 6 and hepcidin-25 trajectories between SRs and NSRs.

\subsection{Model-predicted trends in serum and sputum iron between SRs and NSRs}

Median serum iron concentrations at baseline (Table S1) and at PEX onset were not statistically different between SRs and NSRs. The same was true for sputum iron concentrations between SRs and NSRs at these time points. Log transformation was applied to serum iron and sputum iron before modeling, as the two variables were highly right-skewed. The LMMs for log-transformed serum iron and sputum iron revealed that the interaction of cohort and the quadratic time term was significant in both cases (Table S6 and Table S7), again suggesting different time trends for serum iron and sputum iron between SRs and NSRs. The estimated mean trajectories and $95 \%$ Cls for the two variables using the original units of measure scale are shown in Fig. 4. For SRs, the estimated mean of serum iron increased over time and that of sputum iron was relatively stable (Fig. 4A and 4B). For NSRs, the estimated means of the two variables changed in the opposite directions: serum iron initially increased but then decreased (Fig. 4A), while that of sputum iron first decreased and then increased with inflection occurring around day 7 of treatment (Fig. 4B).

When comparing changes in serum and sputum iron during treatment with SRs and NSRs combined, there was a modest negative correlation $(-0.34, p=0.02)$ between the two variables (Fig. S2).

\subsection{Summary of findings about changes in other variables during PEX treatment}

\section{Discussion}

This pilot study characterized the evolution of respiratory symptom burden, lung function, and biochemical indices of iron homeostasis in adults with CF during treatment of PEXs at two accredited care centers. We found that trends in CFRSD-CRISS, a questionnaire that captures short-term changes in the HRQoL of PwCF (48) (Fig. 2), and trends in lung function (FEV1\%) (Fig. 3) differed significantly between two equally sized cohorts treated for similar periods of time (Fig. S1). These findings supported our primary hypothesis that treatment responses would be heterogeneous, which then allowed us to define these subgroups as SRs and NSRs in clinically-meaningful terms. Although SRs and NSRs could not be distinguished by unique trends in serum IL-6 and hepcidin-25 levels during treatment (Tables S4 and S5), trends in serum iron (Fig. 4A, Table S6) and sputum iron (Fig. 4B, Table S7) were distinctly different between these cohorts with divergent PEX treatment responses. We also found that changes in hematologic markers of inflammation (WBC \%N, serum IL-6, and serum hepcidin-25) correlated positively with treatment-related change in CFRSD-CRISS and that changes in FEV1\%, serum iron, TSAT, TIBC and WBC \%L correlated negatively with treatment-related changes in CFRSD-CRISS (Table S9). These associations suggest that iron deficiency in PwCF, as reflected by lower serum iron levels, may be a dynamic and relative state induced by IL- 6 and hepcidin- 25 during PEXs. Our data also identify a possible phenotype for PwCF that does not respond favorably to PEX treatment, one in which serum iron levels initially rise but then fall and sputum iron levels initially fall but then rise.

The association between unfavorable clinical outcomes of PEX treatment and commensurate elevations in sputum iron and reductions in serum iron has not heretofore been reported. This observation is curious in light of in vitro experiments using a bronchial epithelial co-culture model of CF lung infection that identified an etiologic link between transepithelial iron elaboration into airway surface liquid and augmented apical biofilm growth of Pseudomonas aeruginosa when CFTR was rendered dysfunctional by the F508del mutation (49). Lending additional support to the concept that excess iron in the lungs of PwCF is physiologically deleterious is the finding from Hunter et al (50)

Page 5/16 
that higher ferrous iron levels in CF sputum correlated with lower FEV1\% measurements. Data from the current study and our previous work (34) suggest that CF PEXs are characterized by alterations in iron homeostasis. We now question whether incomplete PEX treatment responses are associated with iron transfer from the bloodstream into the airways of PwCF, an idea supported by our finding of a negative correlation between Dserum iron and Dsputum iron during PEx treatment (Fig. S2). However, if this phenomenon occurs during CF PEXs, our data suggest that it is not closely correlated with trends in serum IL-6 (Table S4) and serum hepcidin-25 (Table S5).

Mechanisms by which iron accumulates in the lungs (51) and sputum (34, 50,52-55) of PwCF remain enigmatic. That sputum iron content from PwCF correlated positively with Pseudomonas aeruginosa colony forming units (CFUs) in one study (55) suggests that iron levels are proportional to the quantitative load of bacteria in the CF airway, but other positive correlations between iron and cytokine concentrations and between iron and total cell counts in CF sputum also implicate host factors (55). Here, because we only measured total inorganic iron in sputum, we cannot add to the literature supporting one or both of these possibilities. Nonetheless, our findings support the clinical relevance of excess iron in the lungs of PwCF.

We acknowledge several additional limitations of this work. First, we studied a small sample of twenty subjects (Table 1) and conducted a number of analyses without control for multiple testing. Findings from this investigation, while provocative, should be considered exploratory, requiring confirmation in a larger study. Second, the results, derived from twenty subjects at two CF centers, could limit the generalizability of our observations. However, it is worth noting that these subjects had clinical attributes similar to those of adults with CF during PEXs in other studies $(22,56,57)$. Third, it could be argued that our subjects were more or less symptomatic than most PwCF during PEXs, but the baseline-adjusted LMM coefficient for DCFRSD-CRISS as a function of DFEV1\% $(-0.70, p<0.001)($ Table S9) is similar in magnitude to Spearman correlation coefficients describing this relationship during PEX treatment in the multicenter Standardized Treatment of Pulmonary Exacerbations (STOP) observational study (58). The correspondence between HRQoL and lung function in our study and the STOP study suggests that our subjects were similar to the general CF population. Third, local idiosyncrasies about the diagnosis and treatment of PEXs could have influenced our results. To minimize the impact of practice variation on subject selection, we used the Akron PES (42) to define baseline health and PEX onset at both locations (Tables 1 and S1). Using the Akron PES for this purpose is reasonable because it was designed to standardize prescription of antibiotics for PEXs (42) and because we identified a positive correlation between Akron PES and serum hepcidin-25 in PwCF (59), though we concede that alternative diagnostic criteria are more often used to define PEXs in CF research (60). We did not restrict treatment selection or duration in our study, so it is unclear whether a study in which these factors are controlled would yield similar results.

We encountered missing data in this multiyear study. Most of these missing data resulted from subjects not being able to perform spirometry at PEX onset due to the severity of their respiratory symptoms and from the tendency for subjects to no longer spontaneously expectorate sputum at the end of treatment because they had less chest congestion. To model relationships between variables of interest, we employed LMMs, which can accommodate missing data and address correlations among repeated measurements of a parameter on the same subject (61). Although this statistical technique is appropriate for our study design, we cannot exclude the possibility that our models would have generated different parameter estimates if the study database was more complete.

\section{Conclusions}

In summary, we have shown in this prospective, two-center, observational study of twenty adults with CF who were hospitalized for PEXs that iron homeostasis differed between individuals who did and did not have sustained symptomatic and spirometric responses to treatment with IV antibiotics. These observations suggest that trends in serum iron, TSAT, and TIBC, all of which are easily performed by clinical laboratories, might allow clinicians to identify PwCF whose systemic inflammatory responses to infection do not wane in response to a given treatment regimen. The finding of increased sputum iron content in non-responders to PEX treatment warrants further investigation, especially because compounds that disrupt microbial iron acquisition and utilization are being developed as anti-infective therapies.

\section{Abbreviations}
CF
Cystic fibrosis
CFFPR
Cystic Fibrosis Foundation Patient Registry
CFRD Cystic fibrosis related diabetes
CFRSD
Cystic Fibrosis Respiratory Symptom Diary

Page 6/16 


\begin{tabular}{|c|c|}
\hline CFTR & Cystic fibrosis transmembrane conductance regulator \\
\hline $\mathrm{Cl}$ & Confidence interval \\
\hline CRISS & Chronic Respiratory Infection Symptom Score \\
\hline DHMC & Dartmouth-Hitchcock Medical Center \\
\hline ELISA & Enzyme-linked immunosorbent assay \\
\hline FEV1 & Forced expiratory volume in one second \\
\hline FEV1\% & Percent predicted forced expiratory volume in one second \\
\hline HRQoL & Health related quality of life \\
\hline IL-6 & Interleukin-6 \\
\hline IV & Intravenous \\
\hline LMM & Linear mixed model \\
\hline $\mathrm{MCHC}$ & Mean corpuscular hemoglobin concentration \\
\hline MCV & Mean corpuscular volume \\
\hline MPV & Mean platelet volume \\
\hline MMC & Maine Medical Center \\
\hline NSR & Non-sustained symptom responder \\
\hline PES & Pulmonary exacerbation score \\
\hline PEX & Pulmonary exacerbation \\
\hline PwCF & People with cystic fibrosis \\
\hline RDWCV & Coefficient of variation of the red cell distribution width \\
\hline RDWSD & Standard deviation of the red cell distribution width \\
\hline SD & Standard deviation \\
\hline SR & Sustained symptom responder \\
\hline TIBC & Total iron binding capacity \\
\hline TSAT & Transferrin saturation \\
\hline WBC & White blood cell \\
\hline WBC \%L & Percentage lymphocytes on white blood cell differential \\
\hline WBC $\% \mathrm{~N}$ & Percentage neutrophils on white blood cell differential \\
\hline
\end{tabular}

\section{Declarations}

\section{Acknowledgments}

The authors would like to thank the people with cystic fibrosis and their families from Maine and New Hampshire who graciously participated in this study. 
AHG, DP, and JBZ conceived and designed the study and drafted the manuscript. DBD, MAW, and AB collected and processed biological samples and drafted the manuscript. ABN and TB performed serum cytokine assays and drafted the manuscript. AHG and JH performed statistical analyses. All authors read and approved the final manuscript.

\section{Funding}

This work was supported by the Cystic Fibrosis Foundation through grants to AHG (GIFFOR17Y5) and DP (POLINE17Y5, POLINE18Y7) and by the Dartmouth Clinical and Translational Science Institute under award number KL2TR001088 from the National Center for Advancing Translational Sciences (NCATS) of the National Institutes of Health (NIH). The content is solely the responsibility of the authors and does not necessarily represent the official views of the $\mathrm{NIH}$.

\section{Ethics Approval and Consent to Participate}

The institutional review boards at Dartmouth-Hitchcock Medical Center and Maine Medical Center approved the research protocol. Written informed consent was obtained from study participants.

\section{Consent for Publication}

Not applicable.

\section{Competing Interests Statement}

$A H G, D P, J H, J L D, D B D, M A W, A B N, A B, T B$, and JBZ declare that they do not have any financial, intellectual, or personal conflicts of interest related to this work.

\section{References}

1. Mall MA, Hartl D. CFTR: cystic fibrosis and beyond. The European respiratory journal 2014; 44: $1042-1054$.

2. Martin C, Hamard C, Kanaan R, Boussaud V, Grenet D, Abely M, Hubert D, Munck A, Lemonnier L, Burgel PR. Causes of death in French cystic fibrosis patients: The need for improvement in transplantation referral strategies! Journal of cystic fibrosis : official journal of the European Cystic Fibrosis Society 2016; 15: 204-212.

3. Belkin RA, Henig NR, Singer LG, Chaparro C, Rubenstein RC, Xie SX, Yee JY, Kotloff RM, Lipson DA, Bunin GR. Risk factors for death of patients with cystic fibrosis awaiting lung transplantation. American journal of respiratory and critical care medicine 2006; 173: 659666.

4. Britto MT, Kotagal UR, Hornung RW, Atherton HD, Tsevat J, Wilmott RW. Impact of recent pulmonary exacerbations on quality of life in patients with cystic fibrosis. Chest 2002; 121: 64-72.

5. Dobbin CJ, Bartlett D, Melehan K, Grunstein RR, Bye PT. The effect of infective exacerbations on sleep and neurobehavioral function in cystic fibrosis. American journal of respiratory and critical care medicine 2005; 172: 99-104.

6. Waters V, Stanojevic S, Atenafu EG, Lu A, Yau Y, Tullis E, Ratjen F. Effect of pulmonary exacerbations on long-term lung function decline in cystic fibrosis. The European respiratory journal 2012; 40: 61-66.

7. de Boer K, Vandemheen KL, Tullis E, Doucette S, Fergusson D, Freitag A, Paterson N, Jackson M, Lougheed MD, Kumar V, Aaron SD. Exacerbation frequency and clinical outcomes in adult patients with cystic fibrosis. Thorax 2011; 66: 680-685.

8. Ouyang L, Grosse SD, Amendah DD, Schechter MS. Healthcare expenditures for privately insured people with cystic fibrosis. Pediatric pulmonology 2009; 44: 989-996.

9. Foundation CF. 2018 Annual Registry Report. 2018.

10. Flume PA, Mogayzel PJ, Jr., Robinson KA, Goss CH, Rosenblatt RL, Kuhn RJ, Marshall BC, Clinical Practice Guidelines for Pulmonary Therapies C. Cystic fibrosis pulmonary guidelines: treatment of pulmonary exacerbations. American journal of respiratory and critical care medicine 2009; 180: 802-808.

11. Sanders DB, Bittner RC, Rosenfeld M, Hoffman LR, Redding GJ, Goss CH. Failure to recover to baseline pulmonary function after cystic fibrosis pulmonary exacerbation. American journal of respiratory and critical care medicine 2010; 182: $627-632$.

12. Parkins MD, Rendall JC, Elborn JS. Incidence and risk factors for pulmonary exacerbation treatment failures in patients with cystic fibrosis chronically infected with Pseudomonas aeruginosa. Chest 2012; 141: 485-493. 
13. West NE, Beckett VV, Jain R, Sanders DB, Nick JA, Heltshe SL, Dasenbrook EC, VanDevanter DR, Solomon GM, Goss CH, Flume PA, investigators S. Standardized Treatment of Pulmonary exacerbations (STOP) study: Physician treatment practices and outcomes for individuals with cystic fibrosis with pulmonary exacerbations. Journal of cystic fibrosis : official journal of the European Cystic Fibrosis Society 2017.

14. Schechter MS, VanDevanter DR, Pasta DJ, Short SA, Morgan WJ, Konstan MW, Scientific Advisory G, the I, Coordinators of the Epidemiologic Study of Cystic F. Treatment Setting and Outcomes of Cystic Fibrosis Pulmonary Exacerbations. Annals of the American Thoracic Society 2018; 15: 225-233.

15. Morgan WJ, Wagener JS, Pasta DJ, Millar SJ, VanDevanter DR, Konstan MW, Scientific Advisory Group I, Coordinators of the Epidemiologic Study of Cystic F. Relationship of Antibiotic Treatment to Recovery after Acute FEV1 Decline in Children with Cystic Fibrosis. Annals of the American Thoracic Society 2017; 14: 937-942.

16. VanDevanter DR, Flume PA, Morris N, Konstan MW. Probability of IV antibiotic retreatment within thirty days is associated with duration and location of IV antibiotic treatment for pulmonary exacerbation in cystic fibrosis. Journal of cystic fibrosis : official journal of the European Cystic Fibrosis Society 2016; 15: 783-790.

17. Cogen JD, Oron AP, Gibson RL, Hoffman LR, Kronman MP, Ong T, Rosenfeld M. Characterization of Inpatient Cystic Fibrosis Pulmonary Exacerbations. Pediatrics 2017; 139.

18. Kraynack NC, Gothard MD, Falletta LM, McBride JT. Approach to treating cystic fibrosis pulmonary exacerbations varies widely across US CF care centers. Pediatric pulmonology 2011; 46: 870-881.

19. Gold LS, Patrick DL, Hansen RN, Beckett V, Goss CH, Kessler L. Correspondence between symptoms and preference-based health status measures in the STOP study. Journal of cystic fibrosis : official journal of the European Cystic Fibrosis Society 2018.

20. Sanders DB, Solomon GM, Beckett VV, West NE, Daines CL, Heltshe SL, VanDevanter DR, Spahr JE, Gibson RL, Nick JA, Marshall BC, Flume PA, Goss CH, Group SS. Standardized Treatment of Pulmonary Exacerbations (STOP) study: Observations at the initiation of intravenous antibiotics for cystic fibrosis pulmonary exacerbations. Journal of cystic fibrosis : official journal of the European Cystic Fibrosis Society 2017.

21. Roesch EA, Nichols DP, Chmiel JF. Inflammation in cystic fibrosis: An update. Pediatric pulmonology 2018; 53: S30-S50.

22. Roberts JM, Dai DLY, Hollander Z, Ng RT, Tebbutt SJ, Wilcox PG, Sin DD, Quon BS. Multiple reaction monitoring mass spectrometry to identify novel plasma protein biomarkers of treatment response in cystic fibrosis pulmonary exacerbations. Journal of cystic fibrosis : official journal of the European Cystic Fibrosis Society 2017.

23. Sagel SD, Thompson V, Chmiel JF, Montgomery GS, Nasr SZ, Perkett E, Saavedra MT, Slovis B, Anthony MM, Emmett P, Heltshe SL. Effect of treatment of cystic fibrosis pulmonary exacerbations on systemic inflammation. Annals of the American Thoracic Society 2015; 12: 708-717.

24. Sharma A, Kirkpatrick G, Chen V, Skolnik K, Hollander Z, Wilcox P, Quon BS. Clinical utility of C-reactive protein to predict treatment response during cystic fibrosis pulmonary exacerbations. PloS one 2017; 12: e0171229.

25. Shoki AH, Mayer-Hamblett N, Wilcox PG, Sin DD, Quon BS. Systematic review of blood biomarkers in cystic fibrosis pulmonary exacerbations. Chest 2013; 144: 1659-1670.

26. Reid PA, McAllister DA, Boyd AC, Innes JA, Porteous D, Greening AP, Gray RD. Measurement of serum calprotectin in stable patients predicts exacerbation and lung function decline in cystic fibrosis. American journal of respiratory and critical care medicine 2015; 191: 233-236.

27. Quon BS, Dai DL, Hollander Z, Ng RT, Tebbutt SJ, Man SF, Wilcox PG, Sin DD. Discovery of novel plasma protein biomarkers to predict imminent cystic fibrosis pulmonary exacerbations using multiple reaction monitoring mass spectrometry. Thorax 2016; 71: $216-222$.

28. Mayer-Hamblett N, Ramsey BW, Kronmal RA. Advancing outcome measures for the new era of drug development in cystic fibrosis. Proceedings of the American Thoracic Society 2007; 4: 370-377.

29. Gray RD, Downey D, Taggart CC. Biomarkers to monitor exacerbations in cystic fibrosis. Expert review of respiratory medicine 2017; 11 : 255-257.

30. Nixon LS, Yung B, Bell SC, Elborn JS, Shale DJ. Circulating immunoreactive interleukin-6 in cystic fibrosis. American journal of respiratory and critical care medicine 1998; 157: 1764-1769.

31. Nemeth E, Rivera S, Gabayan V, Keller C, Taudorf S, Pedersen BK, Ganz T. IL-6 mediates hypoferremia of inflammation by inducing the synthesis of the iron regulatory hormone hepcidin. J Clin Invest 2004; 113: 1271-1276.

32. Mena NP, Esparza A, Tapia V, Valdes P, Nunez MT. Hepcidin inhibits apical iron uptake in intestinal cells. American journal of physiology Gastrointestinal and liver physiology 2008; 294: G192-198.

Page 9/16 
33. Theurl I, Theurl M, Seifert M, Mair S, Nairz M, Rumpold H, Zoller H, Bellmann-Weiler R, Niederegger H, Talasz H, Weiss G. Autocrine formation of hepcidin induces iron retention in human monocytes. Blood 2008; 111: 2392-2399.

34. Gifford AH, Moulton LA, Dorman DB, Olbina G, Westerman M, Parker HW, Stanton BA, O'Toole GA. Iron homeostasis during cystic fibrosis pulmonary exacerbation. Clinical and translational science 2012; 5: 368-373.

35. Schmidt PJ. Regulation of Iron Metabolism by Hepcidin under Conditions of Inflammation. J Biol Chem 2015; $290: 18975-18983$.

36. Farrell PM, Rosenstein BJ, White TB, Accurso FJ, Castellani C, Cutting GR, Durie PR, Legrys VA, Massie J, Parad RB, Rock MJ, Campbell PW, 3rd, Cystic Fibrosis F. Guidelines for diagnosis of cystic fibrosis in newborns through older adults: Cystic Fibrosis Foundation consensus report. The Journal of pediatrics 2008; 153: S4-S14.

37. Flume PA, O'Sullivan BP, Robinson KA, Goss CH, Mogayzel PJ, Jr., Willey-Courand DB, Bujan J, Finder J, Lester M, Quittell L, Rosenblatt R, Vender RL, Hazle L, Sabadosa K, Marshall B, Cystic Fibrosis Foundation PTC. Cystic fibrosis pulmonary guidelines: chronic medications for maintenance of lung health. American journal of respiratory and critical care medicine 2007; 176: $957-969$.

38. Mogayzel PJ, Jr., Naureckas ET, Robinson KA, Mueller G, Hadjiliadis D, Hoag JB, Lubsch L, Hazle L, Sabadosa K, Marshall B, Pulmonary Clinical Practice Guidelines C. Cystic fibrosis pulmonary guidelines. Chronic medications for maintenance of lung health. American journal of respiratory and critical care medicine 2013; 187: 680-689.

39. Heck JE, Andrew AS, Onega T, Rigas JR, Jackson BP, Karagas MR, Duell EJ. Lung cancer in a U.S. population with low to moderate arsenic exposure. Environmental health perspectives 2009; 117: 1718-1723.

40. Miller MR, Crapo R, Hankinson J, Brusasco V, Burgos F, Casaburi R, Coates A, Enright P, van der Grinten CP, Gustafsson P, Jensen R, Johnson DC, Maclntyre N, McKay R, Navajas D, Pedersen OF, Pellegrino R, Viegi G, Wanger J. General considerations for lung function testing. The European respiratory journal 2005; 26: 153-161.

41. Ganz T, Olbina G, Girelli D, Nemeth E, Westerman M. Immunoassay for human serum hepcidin. Blood 2008; $112: 4292-4297$.

42. Kraynack NC, McBride JT. Improving care at cystic fibrosis centers through quality improvement. Seminars in respiratory and critical care medicine 2009; 30: 547-558.

43. Goss CH, Edwards TC, Ramsey BW, Aitken ML, Patrick DL. Patient-reported respiratory symptoms in cystic fibrosis. Journal of cystic fibrosis : official journal of the European Cystic Fibrosis Society 2009; 8: 245-252.

44. Goss CH, Caldwell E, Gries KS, Leidy NK, Edwards T, Flume PA, Marshall BC, Ramsey BW, DL P. Validation of a novel patient-reported respiratory symptoms instrument in cystic fibrosis: CFRSD-CRISS. Pediatric pulmonology 2013; 48: $295-296$.

45. Group SQoL. Cystic Fibrosis Respiratory Symptom Diary (CFRSD) - U.S. Version 2.0. Seattle, WA: University of Washington.

46. Ramsey BW, Davies J, McElvaney NG, Tullis E, Bell SC, Drevinek P, Griese M, McKone EF, Wainwright CE, Konstan MW, Moss R, Ratjen F, Sermet-Gaudelus I, Rowe SM, Dong Q, Rodriguez S, Yen K, Ordonez C, Elborn JS, Group VXS. A CFTR potentiator in patients with cystic fibrosis and the G551D mutation. The New England journal of medicine 2011; 365: 1663-1672.

47. Wainwright CE, Elborn JS, Ramsey BW, Marigowda G, Huang X, Cipolli M, Colombo C, Davies JC, De Boeck K, Flume PA, Konstan MW, McColley SA, McCoy K, McKone EF, Munck A, Ratjen F, Rowe SM, Waltz D, Boyle MP, Group TS, Group TS. Lumacaftor-Ivacaftor in Patients with Cystic Fibrosis Homozygous for Phe508del CFTR. The New England journal of medicine 2015; 373 : $220-231$.

48. Bennett AV, Patrick DL, Lymp JF, Edwards TC, Goss CH. Comparison of 7-day and repeated 24-hour recall of symptoms of cystic fibrosis. Journal of cystic fibrosis : official journal of the European Cystic Fibrosis Society 2010; 9: 419-424.

49. Moreau-Marquis S, Bomberger JM, Anderson GG, Swiatecka-Urban A, Ye S, O'Toole GA, Stanton BA. The DeltaF508-CFTR mutation results in increased biofilm formation by Pseudomonas aeruginosa by increasing iron availability. American journal of physiology Lung cellular and molecular physiology 2008; 295: L25-37.

50. Hunter RC, Asfour F, Dingemans J, Osuna BL, Samad T, Malfroot A, Cornelis P, Newman DK. Ferrous iron is a significant component of bioavailable iron in cystic fibrosis airways. mBio 2013; 4.

51. Ghio AJ, Roggli VL, Soukup JM, Richards JH, Randell SH, Muhlebach MS. Iron accumulates in the lavage and explanted lungs of cystic fibrosis patients. Journal of cystic fibrosis : official journal of the European Cystic Fibrosis Society 2013; 12: 390-398.

52. Gifford AH, Miller SD, Jackson BP, Hampton TH, O'Toole GA, Stanton BA, Parker HW. Iron and CF-related anemia: expanding clinical and biochemical relationships. Pediatric pulmonology 2011; 46: 160-165.

53. Gray RD, Duncan A, Noble D, Imrie M, O'Reilly DS, Innes JA, Porteous DJ, Greening AP, Boyd AC. Sputum trace metals are biomarkers of inflammatory and suppurative lung disease. Chest 2010; 137: 635-641.

54. Smith DJ, Anderson GJ, Bell SC, Reid DW. Elevated metal concentrations in the CF airway correlate with cellular injury and disease severity. Journal of cystic fibrosis : official journal of the European Cystic Fibrosis Society 2014; 13: $289-295$.

55. Reid DW, Carroll V, O'May C, Champion A, Kirov SM. Increased airway iron as a potential factor in the persistence of Pseudomonas aeruginosa infection in cystic fibrosis. The European respiratory journal 2007; 30: 286-292.

Page $10 / 16$ 
56. Horsley AR, Davies JC, Gray RD, Macleod KA, Donovan J, Aziz ZA, Bell NJ, Rainer M, Mt-lsa S, Voase N, Dewar MH, Saunders C, Gibson JS, Parra-Leiton J, Larsen MD, Jeswiet S, Soussi S, Bakar Y, Meister MG, Tyler P, Doherty A, Hansell DM, Ashby D, Hyde SC, Gill DR, Greening AP, Porteous DJ, Innes JA, Boyd AC, Griesenbach U, Cunningham S, Alton EW. Changes in physiological, functional and structural markers of cystic fibrosis lung disease with treatment of a pulmonary exacerbation. Thorax 2013; 68 : 532-539.

57. Gray RD, Imrie M, Boyd AC, Porteous D, Innes JA, Greening AP. Sputum and serum calprotectin are useful biomarkers during CF exacerbation. Journal of cystic fibrosis : official journal of the European Cystic Fibrosis Society 2010; 9: 193-198.

58. Gold LS, Patrick DL, Hansen RN, Goss CH, Kessler L. Correspondence between lung function and symptom measures from the Cystic Fibrosis Respiratory Symptom Diary-Chronic Respiratory Infection Symptom Score (CFRSD-CRISS). Journal of cystic fibrosis : official journal of the European Cystic Fibrosis Society 2019.

59. Gifford AH, Alexandru DM, Li Z, Dorman DB, Moulton LA, Price KE, Hampton TH, Sogin ML, Zuckerman JB, Parker HW, Stanton BA, O'Toole GA. Iron supplementation does not worsen respiratory health or alter the sputum microbiome in cystic fibrosis. Journal of cystic fibrosis : official journal of the European Cystic Fibrosis Society 2014; 13: 311-318.

60. Goss CH, Burns JL. Exacerbations in cystic fibrosis. 1: Epidemiology and pathogenesis. Thorax 2007; 62: $360-367$.

61. Cnaan A, Laird NM, Slasor P. Using the general linear mixed model to analyse unbalanced repeated measures and longitudinal data. Statistics in medicine 1997; 16: 2349-2380.

\section{Tables}




\begin{tabular}{|c|c|c|c|c|c|c|c|c|c|c|c|}
\hline Subject & Center & $\begin{array}{l}\text { Age } \\
\text { (yrs) }\end{array}$ & Sex & Genotype & $\begin{array}{l}\text { FEV1, } \\
\text { L } \\
\text { pred) }\end{array}$ & $\begin{array}{l}\text { FVC, } \\
\text { L } \\
\text { (\% } \\
\text { pred) }\end{array}$ & $\begin{array}{l}\text { Weight } \\
\text { (kg) }\end{array}$ & $\begin{array}{l}\text { Akron } \\
\text { PES }\end{array}$ & $\begin{array}{l}\text { CFRSD- } \\
\text { CRISS }\end{array}$ & $\begin{array}{l}\text { Sputum } \\
\text { Culture }\end{array}$ & $\begin{array}{l}\text { Chronic } \\
\text { Medications }\end{array}$ \\
\hline 1 & DHMC & 27 & $\mathrm{~F}$ & F508del x 2 & $\begin{array}{l}2.85 \\
(91)\end{array}$ & $\begin{array}{l}3.70 \\
(101)\end{array}$ & 56.8 & 1 & 23 & $A X$ & $\begin{array}{l}\text { DA, HS, } \\
\text { COL, ICS, } \\
\text { AZTH }\end{array}$ \\
\hline 2 & DHMC & 27 & $M$ & F508del x 2 & $\begin{array}{l}2.42 \\
(50)\end{array}$ & $\begin{array}{l}4.62 \\
(78)\end{array}$ & 69.9 & 0 & 23 & MSSA & $\begin{array}{l}\text { DA, HS, ICS, } \\
\text { TMP-SMX }\end{array}$ \\
\hline 3 & DHMC & 25 & M & F508del x 2 & $\begin{array}{l}4.00 \\
(78)\end{array}$ & $\begin{array}{l}5.53 \\
(88)\end{array}$ & 99.6 & 4 & 34 & PsA & $\begin{array}{l}\text { DA, AZTH, } \\
\text { ICS, COL }\end{array}$ \\
\hline 4 & DHMC & 24 & $\mathrm{~F}$ & F508del x 2 & $\begin{array}{l}2.39 \\
(79)\end{array}$ & $\begin{array}{l}3.56 \\
(102)\end{array}$ & 49.9 & 0 & 29 & MSSA & $\begin{array}{l}\text { DA, HS, } \\
\text { TOB, AZTH }\end{array}$ \\
\hline 5 & DHMC & 20 & M & F508del/G551D & $\begin{array}{l}1.35 \\
(36)\end{array}$ & $\begin{array}{l}1.91 \\
(44)\end{array}$ & 48.2 & 3 & 34 & $A X$ & $\begin{array}{l}\text { DA, HS, } \\
\text { TOB, ICS, } \\
\text { IVA }\end{array}$ \\
\hline 6 & DHMC & 38 & $\mathrm{~F}$ & F508del $\times 2$ & $\begin{array}{l}0.56 \\
(23)\end{array}$ & $\begin{array}{l}1.22 \\
(41)\end{array}$ & 44.0 & 4 & 52 & $\begin{array}{l}\text { MRSA, } \\
\text { PsA }\end{array}$ & $\begin{array}{l}\text { DA, HS, } \\
\text { TOB, AZTH, } \\
\text { PRED }\end{array}$ \\
\hline 7 & DHMC & 30 & $M$ & F508del/621+1T>G & $\begin{array}{l}0.90 \\
(22)\end{array}$ & $\begin{array}{l}1.77 \\
(36)\end{array}$ & 65.1 & 0 & 34 & PsA & $\begin{array}{l}\text { DA, HS, } \\
\text { AZTH, COL }\end{array}$ \\
\hline 8 & DHMC & 32 & M & F508del x 2 & $\begin{array}{l}2.84 \\
(77)\end{array}$ & $\begin{array}{l}4.08 \\
(91)\end{array}$ & 66.2 & 1 & 23 & $\mathrm{BC}$ & $\begin{array}{l}\text { DA, HS, } \\
\text { COL, TMP- } \\
\text { SMX }\end{array}$ \\
\hline 9 & DHMC & 20 & $\mathrm{~F}$ & F508del/G542X & $\begin{array}{l}1.65 \\
(50)\end{array}$ & $\begin{array}{l}2.52 \\
(67)\end{array}$ & 50.8 & 0 & 41 & BG & DA, HS \\
\hline 10 & DHMC & 25 & $M$ & F508del x 2 & $\begin{array}{l}3.21 \\
(70)\end{array}$ & $\begin{array}{l}4.56 \\
(83)\end{array}$ & 60.5 & 1 & 41 & $\begin{array}{l}\text { MRSA, } \\
\text { PsA }\end{array}$ & $\mathrm{DA}, \mathrm{HS}, \mathrm{AZ}$ \\
\hline 11 & DHMC & 46 & M & F508del/621+1T>G & $\begin{array}{l}0.96 \\
(25)\end{array}$ & $\begin{array}{l}1.75 \\
(36)\end{array}$ & 70.6 & 3 & 41 & $\begin{array}{l}\text { MRSA, } \\
\text { PsA }\end{array}$ & $\begin{array}{l}\text { DA, HS, } \\
\text { AZTH, COL, } \\
\text { DOX }\end{array}$ \\
\hline 12 & DHMC & 33 & $\mathrm{~F}$ & F508del/G542X & $\begin{array}{l}0.96 \\
(34)\end{array}$ & $\begin{array}{l}1.42 \\
(42)\end{array}$ & 43.1 & 2 & 29 & $\begin{array}{l}\text { MRSA, } \\
\text { PsA }\end{array}$ & $\begin{array}{l}\text { DA, HS, } \\
\text { AZTH, COL, } \\
\text { TOB }\end{array}$ \\
\hline 13 & DHMC & 27 & $\mathrm{~F}$ & F508del $\times 2$ & $\begin{array}{l}1.96 \\
(64)\end{array}$ & $\begin{array}{l}3.05 \\
(86)\end{array}$ & 56.9 & 0 & 23 & $\mathrm{BM}, \mathrm{HI}$ & $\begin{array}{l}\text { DA, TOB, } \\
\text { AZTH, } \\
\text { LUM/IVA }\end{array}$ \\
\hline 14 & DHMC & 35 & $\mathrm{~F}$ & F508del/I148T & $\begin{array}{l}1.42 \\
(46)\end{array}$ & $\begin{array}{l}2.45 \\
(65)\end{array}$ & 57.6 & 1 & 37 & $\begin{array}{l}\text { MSSA, } \\
\text { PsA }\end{array}$ & $\begin{array}{l}\text { HS, AZ, } \\
\text { AZTH }\end{array}$ \\
\hline 15 & DHMC & 27 & $\mathrm{~F}$ & F508del $\times 2$ & $\begin{array}{l}1.39 \\
(39)\end{array}$ & $\begin{array}{l}2.77 \\
(66)\end{array}$ & 57.8 & 3 & 44 & $\begin{array}{l}\text { MSSA, } \\
\text { BV }\end{array}$ & $\mathrm{DA}, \mathrm{AZ}$ \\
\hline 16 & MMC & 34 & M & F508del $\times 2$ & $\begin{array}{l}1.08 \\
(26)\end{array}$ & $\begin{array}{l}2.34 \\
(46)\end{array}$ & 72.1 & 0 & 37 & MSSA & $\begin{array}{l}\text { DA, HS, AZ, } \\
\text { LUM/IVA }\end{array}$ \\
\hline 17 & MMC & 20 & $\mathrm{~F}$ & F508del/394delTT & $\begin{array}{l}2.14 \\
(71)\end{array}$ & $\begin{array}{l}2.88 \\
(85)\end{array}$ & 47.7 & 0 & 34 & MRSA & DA, HS, ICS \\
\hline 18 & MMC & 35 & M & F508del $\times 2$ & $\begin{array}{l}1.92 \\
(41)\end{array}$ & $\begin{array}{l}2.58 \\
(45)\end{array}$ & 59.9 & 4 & 52 & $\begin{array}{l}\text { PsA, } \\
\text { MSSA }\end{array}$ & DA \\
\hline 19 & MMC & 22 & M & F508del $\times 2$ & $\begin{array}{l}1.07 \\
(24)\end{array}$ & $\begin{array}{l}1.98 \\
(37)\end{array}$ & 71.5 & 1 & 37 & $\begin{array}{l}\text { PSA, } \\
\text { MSSA }\end{array}$ & $\begin{array}{l}\text { DA, HS, ICS, } \\
\text { AZ }\end{array}$ \\
\hline 20 & MMC & 52 & $\mathrm{~F}$ & $2789+5 G>A / A / 3659 \mathrm{del} C$ & $\begin{array}{l}1.06 \\
(35)\end{array}$ & $\begin{array}{l}1.70 \\
(44)\end{array}$ & 74.0 & 0 & 49 & PsA & $\begin{array}{l}\text { DA, HS, AZ, } \\
\text { PRED }\end{array}$ \\
\hline Mean & & 29.9 & & & 1.80 & 2.8 & 61.1 & 1.4 & 35.9 & & \\
\hline
\end{tabular}




\section{Figures}

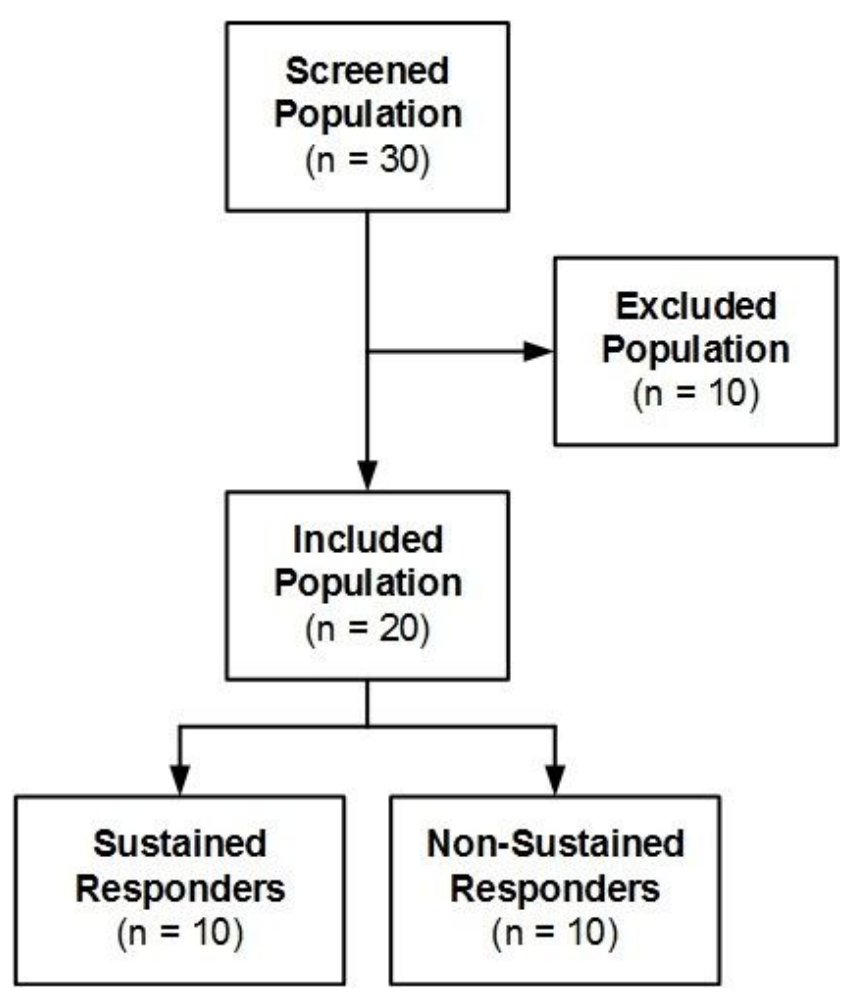

Figure 1

Figure 1 

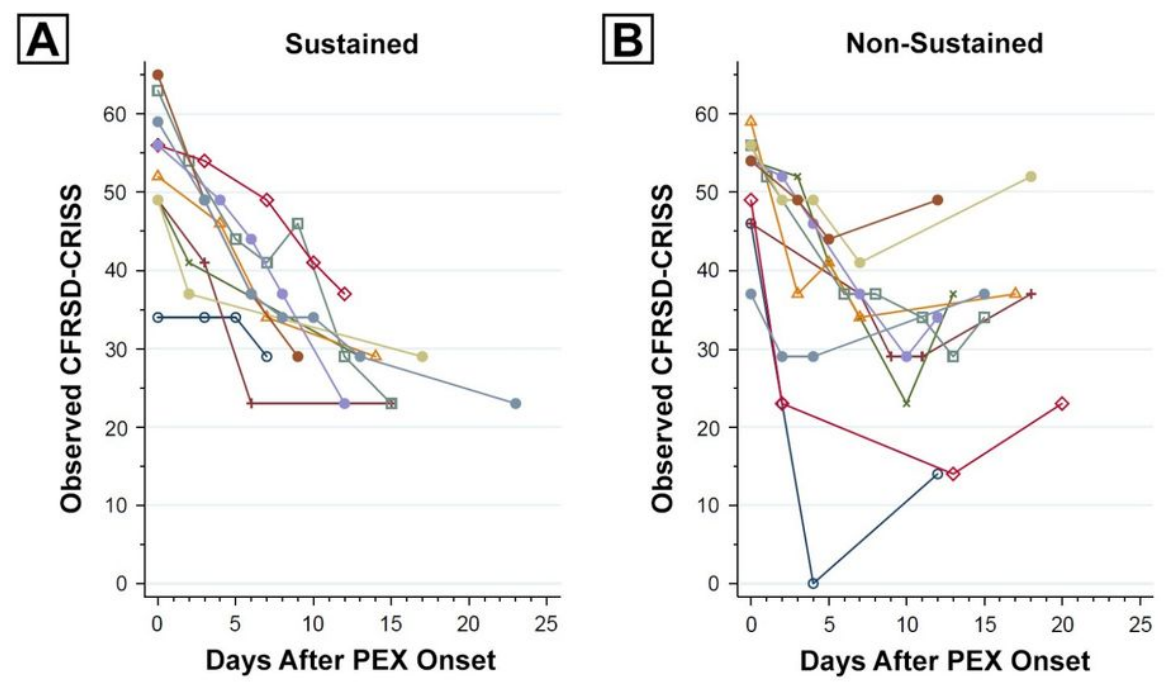

C

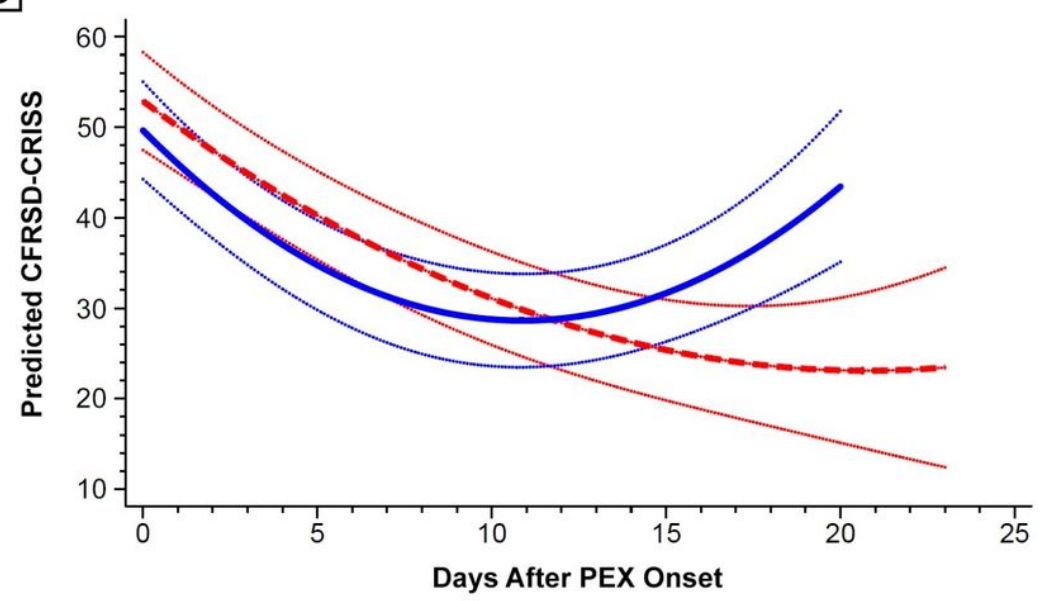

=-ோ- Sustained Non-Sustained

Figure 2

Figure 2 


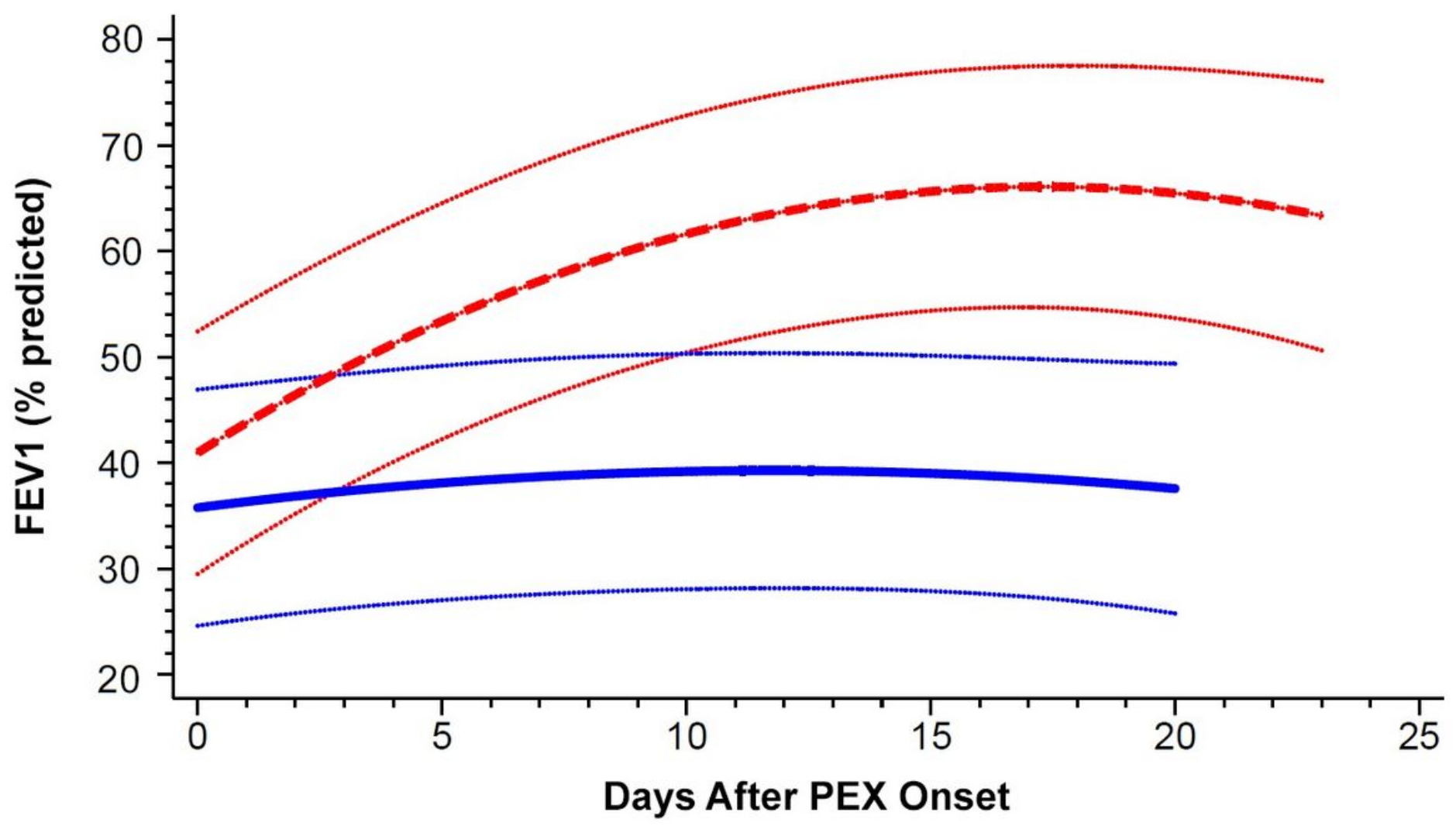

-ேー・-Sustained Non-Sustained

Figure 3

Figure 3 

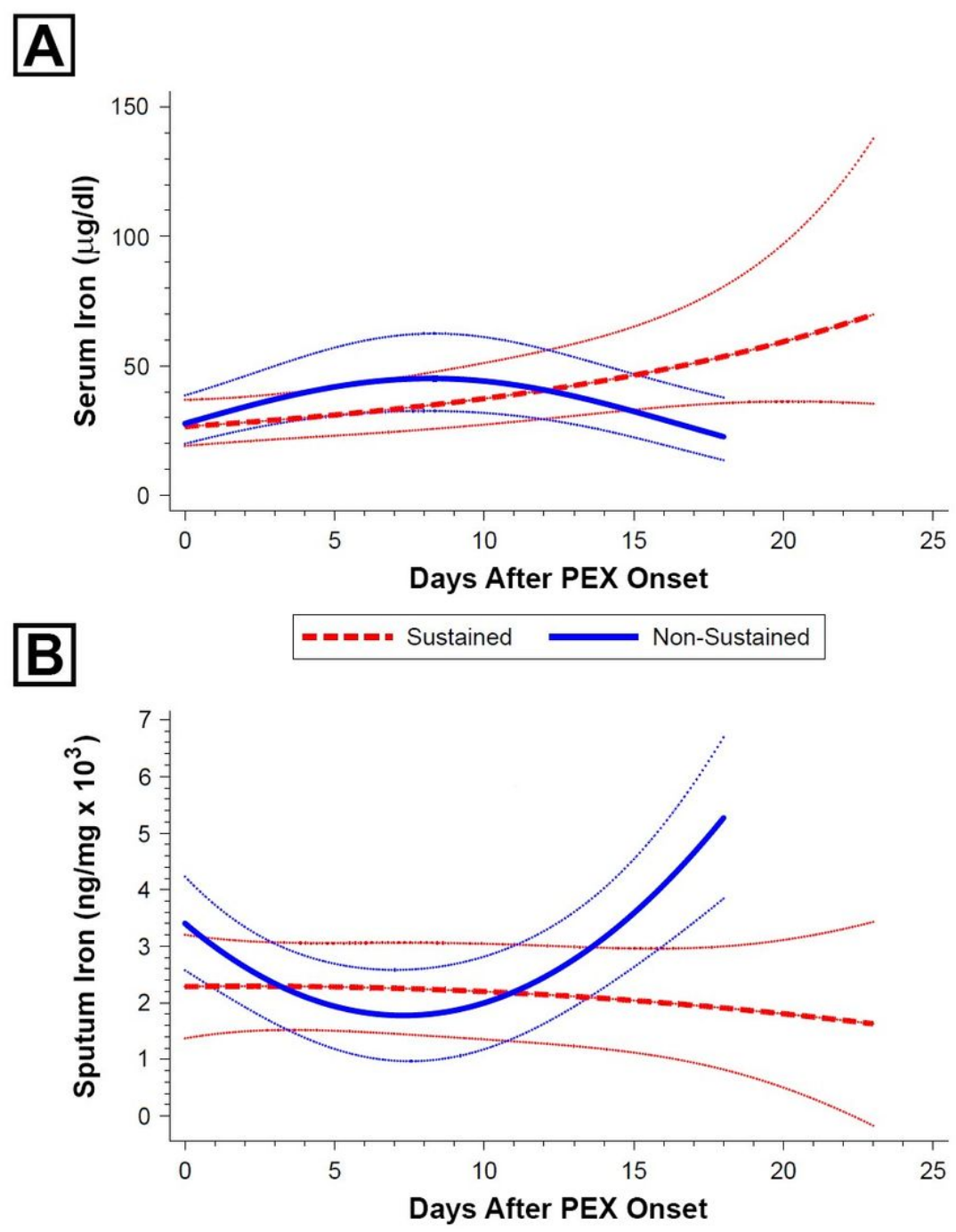

ロேーー Sustained Non-Sustained

\section{Figure 4}

Figure 4

\section{Supplementary Files}

This is a list of supplementary files associated with this preprint. Click to download.

- SupplementalMaterial.docx 